DOI: https://doi.org/10.47405/mjssh.v5i6.427

$\begin{array}{cc}\text { Malaysian Journal of Social Sciences and Hum } & \text { Malian Journal of } \\ \begin{array}{c}\text { Mocial Sciences and } \\ \text { Humanities } \\ \text { (MJ - SSH) }\end{array} & \text { Volume 5, Issue 6, June } 2020 \\ & \text { e-ISSN : 2504-8562 } \\ & \text { Journal home page: } \\ & \text { www.msocialsciences.com }\end{array}$

\title{
Cognitive Behavioural Group Therapy on Test Anxiety Among Primary School Students
}

\author{
Charles Ganaprakasam ${ }^{1}$, Tinagaran Selvaraja ${ }^{2}$ \\ 1Department of Educational Psychology and Counselling, Faculty of Education, University of Malaya (UM) \\ 2Faculty of Education, Sultan Idris Education University (UPSI) \\ Correspondence: Charles Ganaprakasam (ganaprakasamcharles@gmail.com)
}

\begin{abstract}
In an examination-oriented culture, test anxiety becomes a vital hindrance among students, leading to them developing a false belief concerning their innate capabilities. By implementing cognitive behavioral group therapy, students will develop a positive outlook and reduce test anxiety. The present study was aimed at examining the effectiveness of cognitive behavioral group therapy in alleviating test anxiety among primary school students. The study employed one-group pretest-posttest design. The sample of this study consists of forty $(n=40)$ primary school students. Before cognitive behavioral group therapy, respondents completed the Westside Test Anxiety Scale (Driscoll, 2004). Respondents participated in four sessions of cognitive behavioral group therapy. Afterwards, the Westside Test Anxiety Scale was administered as a post-test. Findings revealed a reduction in test anxiety scores among the respondents who have received cognitive behavioral group therapy. Based on these findings, training of this paradigm should be implemented at primary school level as a preventative initiative to alleviate student test anxiety. The results of the present study are encouraging and should be re-examined with a larger sample size.
\end{abstract}

Keywords: test anxiety, cognitive behavioral group therapy, primary school

\section{Introduction}

"I panicked and almost forgot what I had learned when I was in the examination hall".

Anticipating a test, feels like a critical threat for students, especially those facing school exam. The fear of exam tests not only affects functional cognition, but also harms academic achievement. Although studies have shown that moderate level of anxiety move forward an individual to the desired goal, the extremes may end with a number of concerns (Kahan, 2008 \& Donnelly, 2009). For the past few years, several previous works been concentrated in investigating test anxiety among students in tertiary education (Karjanto \& Yong, 2015; Saravanan, Kingston \& Gin, 2014; Vitasari, Wahab, Othman, Herawan \& Sinnadurai 2010). Due to the lack of number of studies involves children, the present study aimed to analyze the efficiency of cognitive behavioral group therapy in alleviating test anxiety among primary school students.

Test anxiety is a notable issue among students in various educational contexts. It is a universal factor negatively affecting students' academic achievement. This critical complex dimension associates individual cognitive and emotion distinction with behavioral response. According to Vitasari, Wahab, 
Othman, Herawan, \& Sinnadurai (2010), the prime symptom of anxiety begins with poor academic development and a minimal amount of interest, and gradually worsens with increasing instability.

Various detrimental factors associated with test anxiety may occur before, during and after any examination. The most prominent factors are poor academic performance and dropping out of school. Students tend to experience several abnormal emotional difficulties due to feeling threatened about examinations and may stop attending school. Tahmasebipour (2011) has shown that many students in tertiary education suffer from test anxiety even after spending time preparing themselves for a test. Much work on identifying the crucial factors towards test anxiety has been found. A study by Khosravi, Ostovar, Azami (2012) discovered that teacher expectation, family environmental elements and the students' own personalities are factors related to test anxiety.

According to the Interference Model Theory (Birjandi \& Alemi, 2010), test anxiety plays a very important role in detrimental decay. It has been suggested that test anxiety causes an individual to experience unrelated emotional and behavioral responses in the examination context by causing interruption with several irrelevant thoughts. An appropriate level of anxiety among students enables them to work towards their planned target. In an examination-oriented culture, test anxiety is a vital hindrance amongst students, leading to the development of false beliefs concerning their innate capabilities. The researcher has identified that test anxiety directly impacts individual self-esteem and promotes destructive cognitive estimation or judgment, deficient concentration, and uncomfortable physiological responses (Sarason, 1978). With this in mind, we expect substantial association of test anxiety with a student's examination results.

According to Zeidner (1998), anxiety about tests involves multiple elements such as phenomenology, physiology and behavior that cause a person to be frustrated by negative beliefs about test or evaluation results. According to Asadullapoor, Fati, \& Gharaee (2010), anxiety is an unpleasant feeling that results in imbalances in human thinking and behavior. Disciplined students exhibit passive behaviors such as lack of interest in education, impaired academic achievement, and often do not work in school. Psychological symptoms such as anxiety and panic in the examination hall and physiological symptoms such as sweating in the palms, cold sweats, rapid heartbeat, and abdominal pain are among the visible effects when a student experiences anxiety (Ruffins, 2007).

\section{Cognitive Behavioral Group Therapy}

Cognitive behavioral therapy is a psychological intervention used to treat individuals with various anxiety disorders. This psychological intervention enables an individual to comprehend the ultimate process of connection between his or her thoughts, behaviors and emotions. It also emphasizes that an individual's own underestimation regarding their capabilities leads to discomfort and the feelings of being threatened. Anxiety is a common disorder able to be treated effectively by CBT (Watts, Turnell, Kladnitski, Newby, \& Andrews, 2015).

In the 1950s, prominent psychologists such as B.F. Skinner and Joseph Wolpe established the [Author7] behavioral therapy movement by proposing the association between behavior and emotion and the cognitive state, such as appraisals. Behaviorists stated that changes in behavior often resulted in improvements in emotion and the individual way of thinking. However, several years later psychologists Albert Ellis and Aoran T. Beck expanded the notion of behavioral therapy to include cognitive elements as a prime factor. Compared to the Behaviorist viewpoint, their analyses have found that changing one's cognition may have the ability to alter both emotion and behavior. Ultimately, the prime elements in therapy, namely behavior and cognitive factors, emerged to become cognitive-behavioral therapy. 
DOI: https://doi.org/10.47405/mjssh.v5i6.427

\section{Cognitive Behavioral Therapy On Test Anxiety}

Appreciating the need for empirical based intervention focusing on test anxiety among primary school students, our research endeavored to examine the effectiveness of cognitive behavioral group therapy on decreasing test anxiety as an initial stage of intervention. A growing body of literature shows that test anxiety can be reduced following the successful modification of CBT (Isenberg, 2012; Fayand, Gargari, \& Sarandi, 2013). We examined the effectiveness of cognitive behavioral group therapy by providing four classroom-based session, with a focus on modifying elements in cognitive behavioral therapy without changing the core concept of that approach in order to reduce test anxiety.

Cognitive behavioral therapy is used to recognize destructive thoughts with several techniques such as diagnosed inappropriate thoughts, challenging and changing maladaptive thoughts, and exploring evidence for and against automatic thoughts (Antonia, Kaczkurkin, \& Foa, 2015). Apart from these, cognitive restructuring is one of the most widely used techniques in cognitive behavioral therapy to improve individual ways of thinking to be more constructive. The present study utilized the cognitive restructuring method in the group therapy sessions. After every session, students received homework such as worksheets to help them gain mastery of these skills and allow them to use them in their daily lives.

In treating test anxiety, Beck proposed that individual belief is the main factor that should be altered. Altering or restructuring an individual's negative feelings to positive could improve one's life (Fayand, Gargari, \& Sarandi, 2013). The researchers provided four sessions of cognitive therapy training to the group to examine the effectiveness of cognitive behavioral group therapy in reducing test anxiety. They expected that changing student cognition would impact their behavior. Students were taught to identify destructive thinking to help them to develop a positive outlook and train them to apply a new way of positive thinking.

Therefore, this study aimed to fulfil the following objectives:

i. To examine the effectiveness of cognitive behavioral group therapy on test anxiety among primary school students.

Based on these, two hypotheses were formulated:

i. Cognitive behavioral group therapy does curtail test anxiety among primary school students.

ii. Cognitive behavioral group therapy doesn't curtail test anxiety among primary school students.

\section{Methodology}

\section{Research design}

This study employed one-group pretest-posttest design. A one-group pretest-posttest design is a type of research design that is most often utilized by behavioral researchers to determine the effect of a treatment or intervention on a given sample (Alan, 2017)

\section{Population and Study Sample}

The population of this study included 104 Fifth Year students. From this population, forty $(\mathrm{N}=40)$ students were sampled from among 11-year-old Fifth Year students. Samples were selected using a random sampling method.

\section{Research tools}

This study employed the Westside Test Anxiety Scale which is a 10-item test which identifies test anxiety levels among students. This instrument has been used by school counsellors in a number of studies to evaluate levels of student examination anxiety (Driscoll, 2004). This questionnaire has been 
DOI: https://doi.org/10.47405/mjssh.v5i6.427

tested for both reliability and validity. Nunnally (1978) states that study instruments should provide a reliability value of 0.70 or greater. Validity tests should show correlations between items of $\geq 0.30$ (Sekaran, 2003). This questionnaire's reliability has been confirmed, with a Cronbach's Alpha of 0.934 .

\section{Structure of the session}

The activity plan for the intervention consisted of a number of activities focused on cognitive restructuring. The intervention was carried out four times in one month with each session lasting 1 hour and 30 minutes. Each session was divided into two phases. The first phase focused on instruction, while the second phase focused on group training in the form of a simulation. The following sessions were implemented.

First session: The researchers administered the pre-test questionnaire, and were exposed to the basics of cognitive behavioral therapy and its application methods.

Second session: The researchers asked the students to identify negative thoughts and express the relationship between these thoughts and their emotions, based on the examples given.

Third session: The researchers asked the participants to identify negative opinions among students about examinations. Researcher then provided explanations of the impacts of these negative thoughts on student emotions and behavior. Then, the researchers taught students how to replace negative emotions with positive emotions, a technique known as cognitive restructuring which is one of the core elements of cognitive behavior therapy. Studies have shown that this technique is able to reduce the effects of anxiety disorder and may help optimize an individual's sense of mental well-being (Barrera, Szafranski, Ratcliff, Garnaat, \& Norton, 2016)

Fourth session: The researcher administered a post-test questionnaire of test anxiety.

\section{Result}

A total of 40 students were tested for anxiety levels before and after receiving cognitive behavioral group therapy. The students were divided into two groups, experimental and control, with 20 students randomly assigned to each group. Students in the experimental group received cognitive behavioral group therapy while students in the control group did not receive any training. The demographic profiles of participants are presented in Table 1 .

Table 1: Demographic of Participants

\begin{tabular}{ccc}
\hline Demographic info & Frequency & Percentage \\
\hline Gender & & \\
1. Male & 17 & $42.5 \%$ \\
2. Female & 23 & $57.5 \%$ \\
\hline
\end{tabular}

A Wilcoxon $\mathrm{T}$ was used to identify the effectiveness of cognitive behavioral group therapy among respondents (Table 2, and Table 3). Result indicated significant difference, score $Z=2.3, p>0.5$, wherein the reduction of mean score of post-tests $(M=1.42)$ from initial pre-test $(M=4.83)$. Finding suggests that cognitive behavioral group therapy effectively reduce test anxiety among primary school students.

Table 2: Mean Score of Test Anxiety among Experimental Group $(\mathrm{N}=40)$

\begin{tabular}{ll}
\hline & M \\
\hline Pre-Test (Test Anxiety Scale) & 4.83 \\
\hline
\end{tabular}


DOI: https://doi.org/10.47405/mjssh.v5i6.427

\begin{tabular}{ll}
\hline Post-Test (Test Anxiety Scale) & 1.42 \\
\hline
\end{tabular}

Table 3: Mean Score

\begin{tabular}{ll}
\hline & M \\
\hline Z & 2.31 \\
Asymp.Sig.(2-tailed) & 0.00 \\
\hline
\end{tabular}

Table 4 shows the reduction of mean score in every domain of test anxiety among primary school students after received cognitive behavioral group therapy. The significant reduction of mean score was noticeable in domain 1 (The closer I am to a major exam, the harder it is for me to concentrate on the material) and in domain 4 (I lose focus on important exams, and I cannot remember material that I knew before the exam).

Table 4: Mean score based on items

\begin{tabular}{lcc}
\hline Domain & $\begin{array}{c}\text { Pre-test } \\
(\boldsymbol{M})\end{array}$ & Post-test (M) \\
\hline $\begin{array}{l}\text { The closer I am to a major exam, the harder it } \\
\text { is for me to concentrate on the material }\end{array}$ & 47.3 & 41.0 \\
$\begin{array}{l}\text { When I study, I worry that I will not remember } \\
\text { the material on the exam. }\end{array}$ & 40.0 & 32.0 \\
$\begin{array}{l}\text { During important exams, I think that I am doing } \\
\text { awful or that I may fail. }\end{array}$ & 27.7 & 25.1 \\
$\begin{array}{l}\text { I lose focus on important exams, and I cannot } \\
\text { remember material that I knew before the exam. }\end{array}$ & 27.3 & 21.9 \\
$\begin{array}{l}\text { I finally remember the answer to exam questions } \\
\text { after the exam is already over. }\end{array}$ & 32.1 & 28.3 \\
$\begin{array}{l}\text { I worry so much before a major exam that I am } \\
\text { too worn out to do my best on the exam. }\end{array}$ & 27.7 & 25.6 \\
$\begin{array}{l}\text { I feel out of sorts or not really myself when I } \\
\text { take important exams. }\end{array}$ & 37.3 & 32.1 \\
$\begin{array}{l}\text { I find that my mind sometimes wanders when I } \\
\text { am taking important exams. }\end{array}$ & 44.7 & 22.3 \\
$\begin{array}{l}\text { After an exam, I worry about whether I did well } \\
\text { enough. }\end{array}$ & 31.3 & 39.5 \\
$\begin{array}{l}\text { I struggle with writing assignments, or avoid } \\
\text { them as long as I can. I feel that whatever I do } \\
\text { will not be good enough. }\end{array}$ & 26.4 & \\
\hline
\end{tabular}

\section{Discussion}

This study investigated the effectiveness of cognitive behavioral group therapy in reducing test anxiety among primary school students. This experimental study revealed that cognitive behavioral group 
therapy improves student capacity to restructure false thoughts and beliefs concerning examination and allowed for more productive thoughts while subsequently reducing levels of test anxiety. Students who received cognitive behavioral group therapy showed a reduction in test anxiety scores due to the understanding concerning the effectiveness of cognitive restructuring. The finding of this study is in line with, several previous studies (Fayand, Badri Gargari \& Sarandi, 2013; Reiss, Warnecke, Tolgou, Krampen, Luka-krausgrill \& Rohrman, 2017). For instance, Reiss et al., (2017) revealed that some strategies of cognitive behavioral therapy such as vivid imagery and relaxation intervention correlate positively towards reducing test anxiety. Experts stated that appropriate exposure of cognitive behavioral therapy intervention skills enable an individual to fight against the maladaptive thoughts and emotions (Sapp, 2013). By this, they gain a sense of mastery over their thoughts and emotions and feel able to perceive them as transient mental events, rather than to identify with them or to believe that thoughts and emotions are accurate reflections of the self or reality.

\section{Implication of Study}

The present findings have several implications. First, it would be of benefit to school administration, especially school guidance and counselling teachers, to comprehend the use of cognitive behavioral group therapy in order to minimize test anxiety, which is common among students. Secondly, whilst anxiety among students is commonplace, abnormal levels of anxiety are associated with poor social adjustment and academic attainment (Owen, Stevenson, Hadwin, Morgate, 2012). In conclusion, it is vital for policymaker, examination bodies, and institutions to make efforts to conduct workshops or student-based intervention at school level to reduce test anxiety, which will enhance academic and coacademic achievements.

\section{Limitation and Suggestion}

This study has only investigated the effectiveness of cognitive behavioral group therapy among primary school students with a limited sample. The findings may not be transferable to the wider community. Given the small size sample, further work should concentrate on maximizing the number of respondents in order to obtain more concrete data on the effectiveness of cognitive behavioral group therapy. Furthermore, this study only concentrated the phenomenon of test anxiety, therefore we propose that further research should be undertaken variables such as suicidal ideation, depression and phobias.

\section{References}

Altairi, Mariam A. (2014). The impact of mindfulness and test anxiety on academic performance. College of Arts \& Sciences Senior Honors Theses. http://doi.org/10.18297/honors/39.

Allen, M. (2017). The sage encyclopedia of communication research methods. Thousand Oaks, CA: SAGE Publications, Inc doi: 10.4135/9781483381411

Asadullapoor, A. Fati, L. \& Gharaee, B. (2010). Metacognitive anxiety and the immediate and delayed judgment of learning. Journal psychiat clinic psychol. 16 (4), 412-19.

Barrera TL, Szafranski DD, Ratcliff CG, Garnaat SL, Norton PJ. 2016. An Experimental Comparison of Techniques: Cognitive Defusion, Cognitive Restructuring, and in-vivo Exposure for Social Anxiety. Behav Cogn Psychother, 44(2):249-254.

Birjandi, P. \& Alemi, M. (2010). The impact of test anxiety on test performance among Iranian EFL learners. BRAIN: Broad Research in Artificial Intelligence \& Neuroscience, 1(4), 44-58.

Bradley, R., McCraty, R., Atkinson, M., Arguelles, L., Rees, R. A., \& Tomasino, D. (2007). Reducing test anxiety and improving test performance in America's schools: Results from the TestEdge national demonstration study. Boulder Creek, CA: HeartMath Research Center, Institute of HeartMath, Publication No. 07-04-01

Cuijpers P, Sijbrandij M, Koole S, Huibers M, Berking M, Andersson G. (2014). Psychological treatment of generalized anxiety disorder: a meta-analysis. Clin Psychol Rev.; 34(2),130-40. 
Donnelly, R. (2009). Embedding interaction within a blend of learner centric pedagogy and technology. World Journal on Educational Technology, 1(1), 6-29.

Dugas M. J., Brillon P., Savard P., Turcotte J., Gaudet A., Ladouceur R., Leblanc R., Gervais N. J. (2010). A randomized clinical trial of cognitive-behavioral therapy and applied relaxation for adults with generalized anxiety disorder. Behav Ther, 41(1), 46-58.

Fayand, J., Badri Gargari, R., \& Sarandi, P. (2013). An investigation of the effects of cognitive therapy training on test anxiety in secondary education. European Journal of Experimental Biology, (3), 116-120.

Fayand, J., Gargari, R. B., \& Sarandi, P. (2013). The impact of mindfulness and test anxiety on academic performance. European Journal of Experimental Biolog, 3(1), 116-120. Retrieved April 23, 2018, from http://www.imedpub.com/articles/an-investigation-of-the-effects-ofcognitive-therapy-training-on-test-anxiety-in-secondary-education.pdf

Kahan, L. M., (2008). THE Correlation of Test Anxiety and Acdemic Performance of Community College Students. Pro Quest LLC jurnal. Capella University. United State.

Khosravi M, Ostovar Z, Azami S, 2012. Test anxiety and its coping styles. Tehran: Elm Publications.

N. Karjanto, S. T. Yong (2015). Test anxiety in mathematics among early undergraduate students in a British university in Malaysia. European Journal of Engineering Education, 38(1), 11-37. doi:10.1080/03043797.2012.742867

Owens, M., Stevenson, J., Hadwin, J. A., \& Morgate, R. (2012). Anxiety and depression in academic performance. An exploration of the mediating factors of worry and working memory. School Psychology International. doi:10.1177/0143034311427433

Reiss, N., Warnecke, I., Tolgou, T., Krampen, D., Luka-Krausgrill, U.,\& Rohrmann, S. (2017). Effects of cognitive behavioral therapy with relaxation vs. imagery rescripting on test anxiety: A randomized controlled trial. Journal of Affective Disorders, 208, 483-489

Ruffin, P. (2007). A Real Fear: It's More Than Stage Fright, Math Anxiety can Derail Academic or Professional Success, But Some Scholars are Working to Help Students Get over It. Diverse Issues in Higher Education. Findarticle.com (online) http://findarticles.com/p/articles/mi_m0WMX/is_2_24/ai_n18744928/

Sapp, M.(2013). Test Anxiety. Applied Research, Assesment, and Treatment Intervention third ed.Lanham, MD: University Press of America.

Sarason, I.G. (1978). The Test Anxiety Scale: Journal of Concept and research. In C.D

Sekaran, U. (2003). Research Methods for Business, a Skill Building Approach 4th edition. Wiley, New Yor Nunnally, J.C. (1978). Psychometric Theory, 2nd edition. McGraw-Hill, New York.

Tahmasebipour N, 2011. Test anxiety (outcomes and methods for controlling it). Tehran: Ghatreh Publications.

Vitasari, P., Wahab, M., Othman, A., Herawan, T., Sinnadurai, S. (2010). The relationship between study anxiety and academic performance among engineering students. ProcediaSocial and Behavioral Sciences, 8, 490-497.

Watts SE, Turnell A, Kladnitski N, Newby JM, Andrews G. 2015. Treatment-as-usual (TAU) is anything but usual: a meta-analysis of CBT versus TAU for anxiety and depression. $J$ Affect Disord, 175, 152-67.

Yousefi, F., Talib.M.,Mansor, B.,Juhari.M.,Redzuan.M.(2010). The Relationship between TestAnxiety and Academic Achievement among Iranian Adolescents. (2010). Asian Social Science, 6(5), 2010th ser., 100-105. doi:10.5539/ass.v6n5p100

Zeidner, M. (1998). Test anxiety: The state of the art. New York: Plenum Press.Psychological treatment of generalized anxiety disorder: a meta-analysis. 